\title{
Long-distance dispersal in red foxes Vulpes vulpes revealed by GPS tracking
}

\author{
Zea Walton $^{1}$ (1) $\cdot$ Gustaf Samelius $^{2} \cdot$ Morten Odden $^{1} \cdot$ Tomas Willebrand $^{1}$ \\ Received: 22 January 2018 / Revised: 26 September 2018 / Accepted: 3 October 2018 / Published online: 11 October 2018 \\ (C) The Author(s) 2018
}

\begin{abstract}
Dispersal is a fundamental process that facilitates population and range expansion by providing a mechanism for colonization and metapopulation linkages. Yet quantifying the dispersal process, particularly long-distance dispersal events, has been inherently difficult due to technological and observational limitations. Additionally, dispersal distance calculated as the straight-line distance between initiation and settlement fails to account for the actual movement path of the animal during dispersal. Here, we highlight six long-distance dispersal events, representing some of the longest dispersal distances recorded for red foxes. Cumulative dispersal movements ranged from 132 to $1036 \mathrm{~km}$ and occurred within both sexes (1 female, 5 males). With one exception, dispersal events ranged from 7 to 22 days and tended to be directed north-northwest. Importantly, cumulative movements were up to five times longer than straight-line distances, with two foxes traveling an additional 114 and $256 \mathrm{~km}$ before returning to, and settling in, areas previously encountered during dispersal. This suggests a role of habitat assessment and homing behavior during dispersal and indicates that the capacity and potential for dispersal are not limiting factors to either sex in a red fox population. Dispersal capacity should thus be considered regarding transboundary management and disease control of red fox populations.
\end{abstract}

Keywords Canid · Dispersal · Long-range movements · Meso-carnivore · Scandinavia · Transboundary management $\cdot$ Range expansion $\cdot$ Disease transmission $\cdot$ Red fox $\cdot$ Norway $\cdot$ Sweden $\cdot$ Global positioning system $($ GPS $)$

\section{Introduction}

Dispersal is a fundamental process in ecology providing the mechanism behind population and range expansion (Sutherland et al. 2000; Lambin et al. 2001). Yet quantifying the dispersal process, particularly long-distance dispersal movements, has been inherently difficult due to technological and observational limitations (Nathan et al. 2003; Nathan 2005; Whitmee and Orme 2013). This also contributes to difficulties defining what represents a long-distance dispersal movement for different species. Long-distance dispersal has been alternately defined as an absolute dispersal distance, or,

Zea Walton

zea.walton@inn.no

$1 \quad$ Faculty of Applied Ecology, Agriculture Sciences and Biotechnology, Department of Forestry and Wildlife Management, Inland Norway University of Applied Sciences, Evenstad, 2480 Koppang, Norway

2 Snow Leopard Trust, 4649 Sunnyside Avenue North, Suite 325, Seattle, WA 98103, USA as those individuals that disperse substantially further than the rest of the population (Nathan 2005). Here, we follow the latter, defining long-distance dispersal as individuals that represent outliers on the spectrum of dispersal distances recorded for a particular species.

Far-ranging individuals and the role that they play in range expansion, colonization, and metapopulation linkages are of great interest to researchers (Shigesada and Kawasaki 2002; Wabakken et al. 2007; Ciucci et al. 2009). Long-distance dispersal events by canids have been previously recognized (wolves Canis lupus (Wabakken et al. 2007); coyotes Canis latrans (Harrison 1992; Kolbe and Squires 2004); red foxes Vulpes vulpes (Allen and Sargeant 1993; Colson et al. 2017)). However, data are scarce and such events are believed to be notable but uncommon (Sutherland et al. 2000; Nathan et al. 2003). Thus, quantifying such movements has largely remained elusive.

Much of the previous knowledge regarding dispersal has relied on capture-mark-recapture studies or very high frequency (VHF) radio tracking technology, where dispersal is often quantified as the straight-line distance between initiation and settlement. However, this fails to account for the actual 
movement path of the animal during dispersal (Storm et al. 1976; Harris and Trewhella 1988; Allen and Sargeant 1993; Gosselink et al. 2010). Further, dispersal data may be of coarse temporal resolution or may fail to record animals dispersing long distances, potentially beyond study area or country boundaries. This oversimplification of dispersal can have implications regarding the extent of dispersal events and the understanding of the dispersal process (Nathan et al. 2003; Whitmee and Orme 2013).

The red fox, a highly adaptable and flexible generalist mesopredator, has successfully colonized most of the northern hemisphere, leading to one of the largest geographic ranges of any terrestrial mammal (Larivière and Pasitschniak-Arts 1996). The behavioral plasticity of red foxes and their ability to respond to landscape productivity changes and human subsidies has allowed them to expand into increasingly northern latitudes, which has direct implications for these ecosystems (Colson et al. 2017; Elmhagen et al. 2015, 2017). Dispersal is a prerequisite for range expansion (Clobert et al. 2001) but our understanding of how long-distance dispersal events may contribute to range expansion remains largely unknown. With advances in GPS and satellite tracking technology, it is now possible to capture dispersal events in their entirety, with high spatial and temporal resolution (Nathan 2005; Cagnacci et al. 2010). This greatly facilitates a more comprehensive quantification of individual dispersal patterns and distances traveled than previously attainable.

Here, we examine six individual long-distance dispersal events by red foxes from three different populations in Norway and Sweden using GPS telemetry. With these data, we aim to improve understanding of the characteristics of long-distance dispersal events of red foxes. Specifically, we quantify both straight-line and cumulative distances traveled, as well as the timing, duration, and directionality of these long-distance dispersal events. Further, we explore whether long-distance movements occur as a multistage process or as single events and discuss their potential implications for northern range expansions and disease transmission.

\section{Methods}

Between 2011 and 2017, we captured 101 red foxes within four different study areas in Sweden and Norway, as part of a longterm research project (see Walton et al. 2017 for details). The four study areas represent a gradient of landscape productivity and human land use. The southernmost study area, Kolmården $\left(58^{\circ} \mathrm{N}\right)$, Sweden, consists of boreonemoral forests, agricultural lands, and scattered human settlements, while northern boreal forests and alpine tundra of low diversity and productivity characterize the northernmost study area in Hedmark County $\left(62^{\circ}\right.$ N), Norway. Norway spruce (Picea abies) and Scots pine (Pinus sylvestris) dominate the forests in all areas, but birch
(Betula pubescens and B. verrucosa) and other deciduous tree species are increasingly present to the south.

All captured foxes $>5 \mathrm{~kg}$ were fitted with GPS radio collars (Tellus Ultralight, 210g, Televilt, Inc. Lindesberg, Sweden). We further sexed, measured, weighed, and aged all captured foxes. Age was defined as sub-adult $(<1$ year) or adult ( $>1$ year) based on the amount of tooth wear and tooth coloration. Additionally, we assumed a birth date of April 1 for young of the year (Harris and Trewhella 1988) to approximate age in months at time of dispersal. For additional description of study areas and capture methodology see Walton et al. (2017).

GPS collars varied in position schedules, with collars deployed before October 2015 programmed to take three positions per day with a drop-off after 270 days ( 9 months), and collars deployed after October 2015 programmed to take six positions per day with a drop-off after 180 days (6 months). We additionally had several foxes captured after 2015 with position data collected at 10-min intervals for up to 3-week periods within their standard six positions per day programming.

We determined foxes engaging in dispersal using net squared displacement (NSD) (Börger and Fryxell 2012; Gurarie et al. 2017), and visual inspection of movement data in QGIS 2.18.0 (Quantum GIS Development Team 2017). Individuals that dispersed straight-line distances greater than $60 \mathrm{~km}$ represented outliers on the spectrum of dispersal distances recorded, and we, thus, defined these individuals $(n=$ 6) as long-distance dispersers following Nathan (2005). To allow comparison of dispersal distances among these foxes, we standardized position interval to three positions per day (the lowest maximum number of positions per day recorded). In total, 6629 GPS positions were available for further analysis. The GPS fix success rate was $98.1 \%$ with a mean horizontal dilution of precision (HDOP) of $1.06 \pm 0.8 \mathrm{SD}$ (range $=$ $0-25.5$ ). Lower HDOP values are considered to be more precise (D'Eon and Delparte 2005) and $99.7 \%$ of positions available had a HDOP < 5.0. We did not have associated HDOP satellite data for one fox, captured in 2012 ( $n=515$ records).

We identified the initiation and end points of dispersal events as the last location in the home range (prior to dispersal), to the first post dispersal location associated with settlement. Three of the six foxes were likely captured while already dispersing, as they had no pre-dispersal area use. In these cases, we classified the dispersal initiation point as the capture location. The end point of dispersal was determined by an individual remaining in the area for more than 8 weeks after dispersal, indicating settlement. However, one fox was killed by a vehicle while dispersing, and here, we classified the mortality site as the end point of dispersal. We then extracted the GPS locations associated with each dispersal movement and determined dates of initiation and end points, dispersal duration, and directionality, using R 3.4.0 (R Core 
Team 2017). We calculated dispersal duration as the number of days between initiation and end points. Directionality was calculated as the geographic bearing of the straight-line between start and end positions. We used a Rayleigh test in the $\mathrm{R}$ package circular (Agostinelli and Lund 2017) to test if there was orientation towards a particular direction during dispersal. Dispersal distance was calculated as both the straight-line distance from initiation point to end point and as the cumulative distance of the dispersal path. We calculated cumulative distance traveled as the sum of the Euclidian distances traveled between successive 8 -h positions (i.e., the movement path) of positions between the start and end points. We further calculated the ratio between cumulative dispersal distance and straight-line distance for each individual.

\section{Results}

Thirty of the 101 red foxes collared in this study dispersed during monitoring. Of these, six foxes traveled straight-line distances greater than $60 \mathrm{~km}$ during their dispersal period. These long-distance dispersers included both sexes (female $=$ 1 , male $=5$ ), with sub-adult males $(67 \%)$ predominantly making these movements. However, one adult male (17\%) and one sub-adult female (17\%) also engaged in these movements (Table 1). Straight-line dispersal distances averaged $60 \% \pm$ $30 \%$ SD (range 20-88\%) of cumulative long-distance dispersal movements. The cumulative dispersal distances ranged from 132 to $1036 \mathrm{~km}$ and were on average $2.3 \pm 1.7 \mathrm{SD}$ times longer than the straight-line distances. The two longest cumulative distances were by a sub-adult female $(1036 \mathrm{~km})$ and a sub-adult male (423 km) (Fig. 1). Two dispersal events were multistaged, with temporary periods of settlement during dispersal. For these foxes, the exploratory movements during their temporary settlement periods were not included in their cumulative dispersal distances (i.e., only those periods when the animal was dispersing were included in the distance calculations). The temporary settlement period for the sub-adult male, Trond, was 8 days. However, the female, Gunnel, had three temporary settlement periods lasting 4,17 , and 19 days respectively. These two foxes later returned to settle in areas they had previously explored, via different movement paths, after traveling an additional 114 and $256 \mathrm{~km}$, respectively. The remaining four dispersal events were single-stage movements of short duration, ranging from 7 to 22 days (Table 1). These single-stage dispersal events occurred quickly, on average $12.5 \pm 6.7 \mathrm{SD}$ days, and were directed movements with cumulative distances averaging only $1.3 \pm 0.1 \mathrm{SD}$ times longer than the straight-line distances. With one exception, long-distance dispersal tended to occur in a north-northwest direction, with a mean geographical bearing of $329^{\circ}$ (range $304^{\circ}-3^{\circ}$ ), though this trend was not statistically significant (Rayleigh's $r=$ $0.6475, p$ value 0.0758 ). Only one fox, from the northernmost study area, dispersed south $\left(186^{\circ}\right)$.

\section{Discussion}

We recorded extraordinary, long-distance dispersal events for red foxes, exceeding expected distances based on body size (Sutherland et al. 2000) and similarly calculated published records for red foxes (Storm et al. 1976; Allen and Sargeant 1993; Gosselink et al. 2010). We found that males, and in particular, sub-adult males, were more prone to engage in

Table 1 Summary of dispersal distances for six red foxes in Norway and Sweden

\begin{tabular}{|c|c|c|c|c|c|c|c|c|c|c|}
\hline FoxID & Sex & $\begin{array}{l}\text { Age at dispersal } \\
\text { (months) }\end{array}$ & $\begin{array}{l}\text { Study } \\
\text { area }\end{array}$ & $\begin{array}{l}\text { Days } \\
\text { monitored }\end{array}$ & $\begin{array}{l}\text { Dispersal } \\
\text { start (date) }\end{array}$ & $\begin{array}{l}\text { Dispersal } \\
\text { end (date) }\end{array}$ & $\begin{array}{l}\text { Dispersal } \\
\text { duration (days) }\end{array}$ & $\begin{array}{l}\text { Cumulative } \\
\text { distance }(\mathrm{km})\end{array}$ & $\begin{array}{l}\text { Straight-line } \\
\text { distance }(\mathrm{km})\end{array}$ & $\begin{array}{l}\text { Dispersal } \\
\text { bearing (degrees) }\end{array}$ \\
\hline Gunde $^{1}$ & M & 10.5 & Hedemora & 111 & $13 \mathrm{Feb}$ & $22 \mathrm{Feb}$ & 9 & 160 & 140 & $304^{\circ}$ \\
\hline Gunnel $^{1}$ & $\mathrm{~F}$ & 11 & Kolmården & 180 & $3 \mathrm{Mar}$ & 11 Jun & $100^{3}$ & 1036 & 255 & $338^{\circ}$ \\
\hline Stefansson $^{1,2}$ & M & 11.5 & Hedemora & 25 & $12 \mathrm{Mar}$ & $2 \mathrm{Apr}$ & 22 & 423 & 294 & $3^{\circ}$ \\
\hline Trond & M & 13 & Hedmark & 50 & 2 May & 31 May & $21^{4}$ & 328 & 67 & $305^{\circ}$ \\
\hline Tufsing & M & 8 & Hedmark & 210 & $30 \mathrm{Nov}$ & $6 \mathrm{Dec}$ & 7 & 133 & 108 & $186^{\circ}$ \\
\hline Wilhelm & M & 23.5 & Kolmården & 188 & $10 \mathrm{Mar}$ & $22 \mathrm{Mar}$ & 12 & 274 & 216 & $334^{\circ}$ \\
\hline
\end{tabular}

Sampling interval is standardized to three positions per day for all foxes (i.e., 8-h intervals). Included are the total dispersal movement distance (Cumulative distance) and straight-line dispersal distance from initiation point to end point. Directionality of dispersal is based on the geographic bearing of the straight-line distance. The dispersal duration includes date of initiation to date of settlement with dispersal duration calculated in days. Two foxes had multistage dispersal (Gunnel and Trond). For these foxes, temporary settlement movements are excluded from cumulative distance but included in dispersal duration. Sex, age at the onset of dispersal, and the total number of days each individual was monitored are also included

${ }^{1}$ Foxes were likely already dispersing upon capture

${ }^{2}$ Fox was killed by vehicle during dispersal

${ }^{3}$ Duration includes 26 days spent navigating dispersal barrier around lake and three temporary settlement periods of four, 17 and 19 days, totaling 66 days during dispersal

${ }^{4}$ Duration includes one temporary settlement period of 9 days during dispersal 


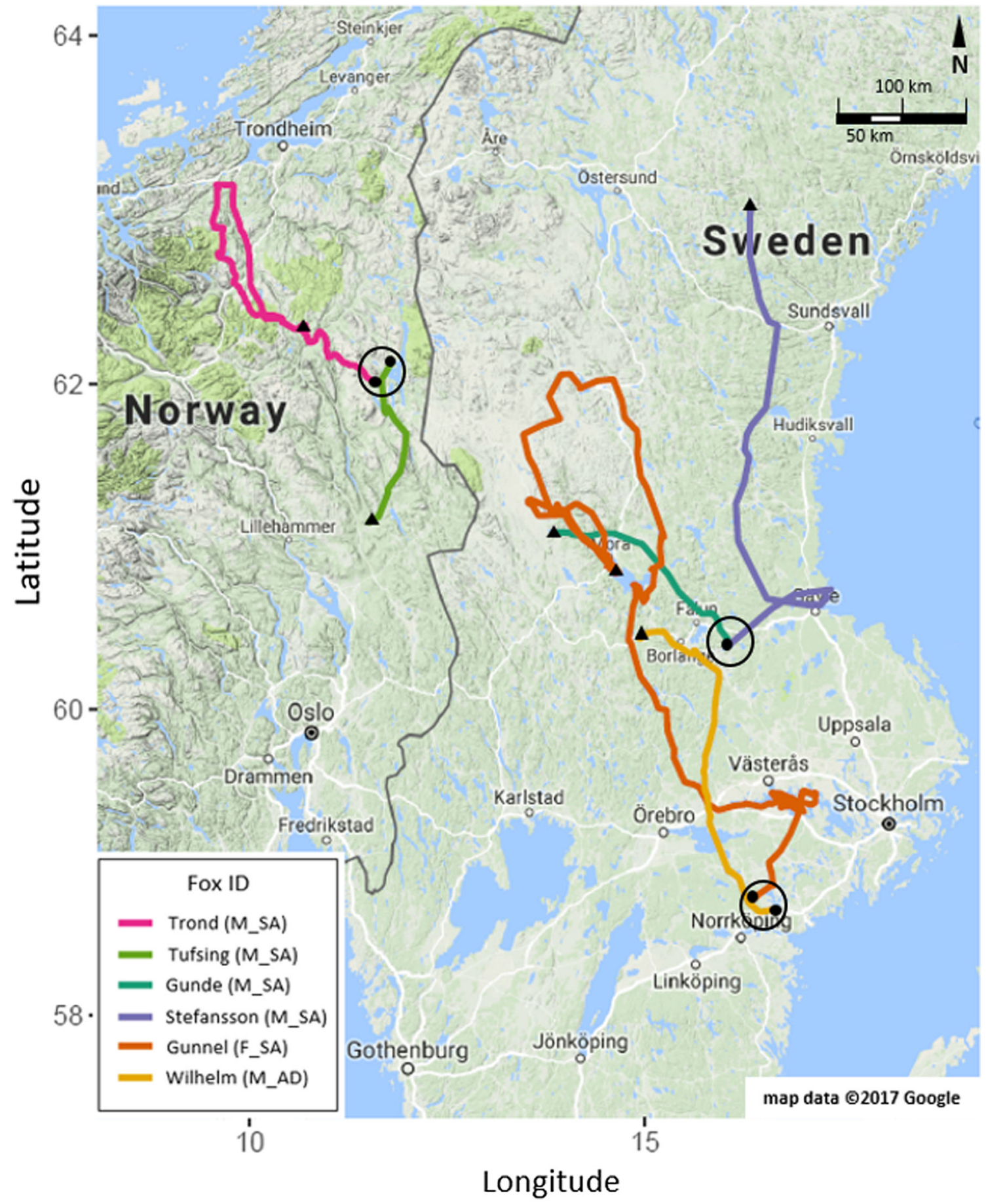

Fig. 1 Long-distance dispersal movements of six GPS-collared red foxes in Sweden and Norway. Solid black circles and triangles indicate initiation (start) and settlement (end) points of dispersal movements, respectively. The three study areas where foxes were initially captured

long-distance dispersal, which follows male-biased dispersal in red foxes, and mammals in general (Storm et al. 1976; Allen and Sargeant 1993; Gosselink et al. 2010). However, similar to the findings by Allen and Sargeant (1993), the longest cumulative dispersal distance $(1036 \mathrm{~km})$ was by a sub-adult female red fox. Genetic data also supports that, while not are outlined by black circles corresponding to Hedmark, Hedemora, and Kolmården, from North to South. The sex and age (sub-adult = SA, adult = AD) of each individual are given in parentheses in the legend

common, female foxes also contribute to long-distance colonization and population expansion via long-distance dispersal movements (Colson et al. 2017). This indicates that the dispersal capacity and potential for dispersal are not limiting factors to either sex in a red fox population (Allen and Sargeant 1993; Norén et al. 2015). 
We further show that long-distance dispersal and settlement occurs very quickly. On average, foxes dispersed distances greater than $100 \mathrm{~km}$ within 2 weeks, illustrating the potential for rapid colonization of new habitats. A comparison of straight-line distance to the cumulative movement distance for single-stage dispersal events also show that cumulative movement distances were on average only 1.3 times longer than straight-line distances. This lends support to dispersal movements being faster and straighter than other types of movements, and follows that found in earlier studies of the species as well (Storm et al. 1976; Kamler et al. 2004; Soulsbury et al. 2011).

Interestingly, with one exception, dispersal events were oriented in a north-northwest direction. A northern dispersal trend has been recognized in other red fox populations found in the northern hemisphere as well (Phillips et al. 1972; Storm et al. 1976; Allen and Sargeant 1993; Gosselink et al. 2010). Northern landscapes of lower productivity likely have lower population densities of red foxes, suggesting that dispersal and settlement may be limited by crowding and competition for available space (Lambin et al. 2001). Additionally, it is also possible that a warming climate, in synergy with agricultural expansion, forestry practices, and anthropogenic subsidies, is increasingly providing suitable habitat north of a red fox's climate-imposed distribution limit, thereby facilitating red fox range expansion into increasingly northern regions (Elmhagen et al. 2015, 2017). A northwestward dispersal direction, in combination with the distances red foxes are capable of traversing, is thus likely contributing to the rapid northern range expansion by red foxes in the northern hemisphere (Allen and Sargeant 1993; Colson et al. 2017; Elmhagen et al. 2017).

Importantly, the total distance traveled during the dispersal events can also be much longer than the distance between initiation and settlement. For example, two foxes ( 1 male, 1 female) had multistage dispersal events rather than single, directed movements, temporarily settling and exploring areas before continuing dispersal. Both foxes returned to settle in areas they had previously explored. However, neither of them returned via the previously used route but circumnavigated though novel terrain to the area they had previously visited. For these foxes, their cumulative dispersal distances were up to five times longer than their respective straight-line distances. Interestingly, Storm et al. (1976) recognized a similar pattern, with multistage dispersal and circular return movements to previously explored areas, in red foxes in the Midwestern USA. This suggests a degree of en route habitat assessment and homing behavior during the dispersal process.

During long-distance dispersal movements, red foxes likely traverse a variety of suitable habitat, both occupied and unoccupied. The presence of other foxes may indicate suitable settlement areas to dispersing foxes, as fox presence itself may act as an indicator of suitable habitat (Lloyd 1980). Conversely, the presence of other foxes may also prevent establishment, as foxes may avoid occupied areas and therefore continue to move, seeking vacant areas for settlement (Lambin et al. 2001), which is concordant with establishment in mammals and birds often being limited by crowding (Wolff 1997).

The proportion of animals that disperse and their dispersal movements may be highly variable among fox populations. Our results showed that only a small proportion of individuals dispersed long distances ( 6 of 101 foxes collared) and these were predominantly sub-adult males, which is in concordance with previous studies (Storm et al. 1976; Trewhella et al. 1988; Allen and Sargeant 1993; Sutherland et al. 2000; Gosselink et al. 2010). Further, our study showed that there appear to be some general commonalities detected for long-distance dispersal movements regarding onset, duration, and geographical orientation. With advances in GPS technology and quantitative tools for analysis of animal movement data, it may be possible to obtain a more precise picture of dispersal and the decisionmaking processes underlying these movements. With these techniques, we can also begin to address important questions involving population dynamics, range expansion, and disease spread (Phillips et al. 1972; Morales et al. 2010).

Although long-distance dispersal is infrequent, our study demonstrates the red fox's ability to traverse between populations, across landscapes, and potentially across international boundaries. Circumpolar data show that red foxes are advancing into increasingly productive tundra (Colson et al. 2017; Elmhagen et al. 2017). As a highly adaptable species, red foxes with strong dispersal abilities likely dominate this expansion front and drive these northern range expansions (Norén et al. 2015). As such, long-distance events are important for the spread of the species (Kot et al. 1996) and have implications for disease transmission (Letková et al. 2006; Vervaeke et al. 2006) and the surrounding ecosystems (Elmhagen et al. 2017). Long-distance dispersal capacity should thus be considered regarding transboundary management, range expansion, and disease control of red fox populations.

Acknowledgements We owe great thanks to Bo Söderberg, Lars Jäderberg, Kent Sköld, Eric Ringby, Fredrik Dahl, Håkon Solvang, Vidar Trøen, Bjørnar Johnsen, and all of the additional people that assisted with field capture and collaring of red foxes. We additionally thank the anonymous reviewers for their comments to the manuscript.

Funding information Funding for this study was provided by the Swedish Environmental Protection Agency, the Swedish Hunters Association, Karl Erik Önnesjös Stiftelse (Sweden), and the Norwegian Directorate for Nature Management and the Gotaas Fund (Norway).

Open Access This article is distributed under the terms of the Creative Commons Attribution 4.0 International License (http:// creativecommons.org/licenses/by/4.0/), which permits unrestricted use, distribution, and reproduction in any medium, provided you give appropriate credit to the original author(s) and the source, provide a link to the Creative Commons license, and indicate if changes were made. 


\section{References}

Agostinelli C, Lund U (2017) R package 'circular': circular statistics (version 0.4-93). URL https://r-forge.r-project.org/projects/circular/

Allen SH, Sargeant AB (1993) Dispersal patterns of red foxes relative to population density. J Wildl Manag 57:526-533

Börger L, Fryxell J (2012) Quantifying individual differences in dispersal using net squared displacement. In: Clobert $\mathrm{J}$ et al (eds) Dispersal ecology and evolution. Oxford University Press, Oxford

Cagnacci F, Boitani L, Powell RA, Boyce MS (2010) Animal ecology meets GPS-based radiotelemetry: a perfect storm of opportunities and challenges. Philos Trans R Soc Lond Ser B Biol Sci 365:21572162. https://doi.org/10.1098/rstb.2010.0107

Ciucci P, Reggioni W, Maiorano L, Boitani L (2009) Long-distance dispersal of a rescued wolf from the northern Apennines to the Western Alps. J Wildl Manag 73:1300-1306. https://doi.org/10. 2193/2008-510

Clobert J, Danchin E, Dhondt AA, Nichols JD (2001) Dispersal. Oxford University Press, Oxford

Colson K, Smith JD, Hundertmark KJ (2017) St. Matthew Island colonized through multiple long-distance red fox (Vulpes vulpes) dispersal events. Can J Zool 95:607-609

D'Eon RG, Delparte D (2005) Effects of radio-collar position and orientation on GPS radio-collar performance, and the implications of PDOP in data screening. J Appl Ecol 42:383-388

Elmhagen B, Kindberg J, Hellstrom P, Angerbjorn A (2015) A boreal invasion in response to climate change? Range shifts and community effects in the borderland between forest and tundra. Ambio 44(Suppl 1):S39-S50. https://doi.org/10.1007/s13280-014-0606-8

Elmhagen B, Berteaux D, Burgess RM, Ehrich D, Gallant D, Henttonen H, Ims RA, Killengreen ST, Niemimaa J, Norén K, Ollila T, Rodnikova A, Sokolov AA, Sokolova NA, Stickney AA, Angerbjörn A (2017) Homage to Hersteinsson and Macdonald: climate warming and resource subsidies cause red fox range expansion and Arctic fox decline. Polar Res 36(sup1). https://doi.org/10.1080/ 17518369.2017.1319109

Gosselink TE, Piccolo KA, van Deelen TR, Warner RE, Mankin PC (2010) Natal dispersal and philopatry of red foxes in urban and agricultural areas of Illinois. J Wildl Manag 74:1204-1217. https:// doi.org/10.2193/2009-108

Gurarie E, Cagnacci F, Peters W, Fleming CH, Calabrese JM, Mueller T, Fagan WF (2017) A framework for modelling range shifts and migrations: asking when, whither, whether and will it return. J Anim Ecol 86:943-959

Harris S, Trewhella WJ (1988) An analysis of some of the factors affecting dispersal in an urban fox (Vulpes vulpes) population. J Appl Ecol 25:409-422

Harrison DJ (1992) Social ecology of coyotes in northeastern North America: relationships to dispersal, food resources, and human exploitation. In: Boer AH (ed) Ecology and management of the eastern coyote. University of New Brunswick Press, Fredericton, pp 53-72

Kamler JF, Ballard WB, Gese EM, Harrison RL, Karki SM (2004) Dispersal characteristics of swift foxes. Can J Zool 82:1837-1842. https://doi.org/10.1139/z04-187

Kolbe JA, Squires JR (2004) Long distance movement by a coyote within the Rocky Mountains. Northwest Sci 78:344-345

Kot M, Lewis MA, van den Driessche P (1996) Dispersal data and the spread of invading organisms. Ecology 77:2027-2042

Lambin X, Aars J, Piertney SB (2001) Dispersal, intraspecific competition, kin competition and kin facilitation: a review of the empirical evidence. Dispersal. Oxford University Press, Oxford

Larivière S, Pasitschniak-Arts M (1996) Vulpes vulpes. Mamm Species:1, 1-1
Letková V, Lazar P, Čurlík J, Goldová M, Kočišová A, Košuthová L, Mojžišová $J$ (2006) The red fox (Vulpes vulpes L.) as a source of zoonoses. Vet Arhiv 76:S73-S81

Lloyd HG (1980) Habitat requirements of the red fox. In: Zimen E (ed) The red fox. Biogeographica. Springer, Dordrecht. https://doi.org/ 10.1007/978-94-017-5592-4_2

Morales JM, Moorcroft PR, Matthiopoulos J, Frair JL, Kie JG, Powell RA, Merrill EH, Haydon DT (2010) Building the bridge between animal movement and population dynamics. Philos Trans R Soc Lond Ser B Biol Sci 365:2289-2301. https://doi.org/10.1098/rstb. 2010.0082

Nathan R (2005) Long-distance dispersal research: building a network of yellow brick roads. Divers Distrib 11:125-130

Nathan R, Perry G, Cronin JT, Strand AE, Cain ML (2003) Methods for estimating long-distance dispersal. Oikos 103:261-273

Norén K, Statham MJ, Ågren EO, Isomursu M, Flagstad Ø, Eide NE, Berg TB, Bech-Sanderhoff L, Sacks BN (2015) Genetic footprints reveal geographic patterns of expansion in Fennoscandian red foxes. Glob Chang Biol 21:3299-3312

Phillips RL, Andrews RD, Storm GL, Bishop RA (1972) Dispersal and mortality of red foxes. J Wildl Manag 36:237-248. https://doi.org/ $10.2307 / 3799056$

Quantum GIS Geographic Information System (2017) Open Source Geospatial Foundation Project. http://qgis.osgeo.org

R Core Team (2017) R: a language and environment for statistical computing R foundation for statistical computing. Austria, Vienna http:// www.R-project.org/

Shigesada N, Kawasaki K (2002) Invasion and the range expansion of species: effects of long-distance dispersal. In: Bullock JM, Kenward RE, Hails RS (eds) Dispersal ecology. Blackwell, Oxford, pp 350 373

Soulsbury CD, Iossa G, Baker PJ, White PCL, Harris S (2011) Behavioral and spatial analysis of extraterritorial movements in red foxes (Vulpes vulpes). J Mammal 92:190-199. https://doi.org/10.1644/ 09-mamm-a-187.1

Storm GL, Andrews RD, Phillips RL, Bishop RA, Siniff DB, Tester JR (1976) Morphology, reproduction, dispersal, and mortality of midwestern red fox populations. Wildl Monogr:3-82

Sutherland GD, Harestad AS, Price K, Lertzman KP (2000) Scaling of natal dispersal distances in terrestrial birds and mammals. Conserv Ecol 4:16

Trewhella WJ, Harris S, McAllister FE (1988) Dispersal distance, homerange size and population density in the red fox (Vulpes vulpes): a quantitative analysis. J Appl Ecol 25:423-434. https://doi.org/10. $2307 / 2403834$

Vervaeke M, van der Giessen J, Brochier B, Losson B, Jordaens K, Verhagen R, Coulander Cde L, Teunis P (2006) Spatial spreading of Echinococcus multilocularis in red foxes (Vulpes vulpes) across nation borders in Western Europe. Prev Vet Med 76:137-150. https://doi.org/10.1016/j.prevetmed.2006.04.014

Wabakken P, Sand H, Kojola I, Zimmermann B, Arnemo JM, Pedersen HC, Liberg O (2007) Multistage, long-range natal dispersal by a global positioning system-collared Scandinavian wolf. J Wildl Manag 71:1631-1634. https://doi.org/10.2193/2006-222

Walton Z, Samelius G, Odden M, Willebrand T (2017) Variation in home range size of red foxes Vulpes vulpes along a gradient of productivity and human landscape alteration. PLoS One 12:e0175291. https:// doi.org/10.1371/journal.pone.0175291

Whitmee S, Orme CD (2013) Predicting dispersal distance in mammals: a trait-based approach. J Anim Ecol 82:211-221. https://doi.org/10. $1111 / j .1365-2656.2012 .02030 . x$

Wolff JO (1997) Population regulation in mammals: an evolutionary perspective. J Anim Ecol 66:1-13 